\title{
Cholesterol control, medication adherence and illness cognition
}

\author{
Noel T. Brewer ${ }^{*}$, Gretchen B. Chapman', Susan Brownlee' and \\ Elaine A. Leventhal ${ }^{2}$ \\ 'Rutgers University, USA \\ ${ }^{2}$ University of Medicine and Dentistry of New Jersey, USA
}

Objective. To examine the relation between illness cognitions and two measures of adherence in patients with hypercholesterolaemia, a disease marked by chronically high cholesterol.

Design. Cross-sectional. Based on the self-regulation model (Leventhal, Diefenbach, \& Leventhal, 1992), patients' illness cognitions were predicted to be related to cholesterol control and medication adherence. Patients with illness cognitions consonant with an experts' mental model of hypercholesterolaemia were expected to show better control and adherence.

Method. Hypercholesterolaemic patients $(N=169)$ were recruited at a universitybased general medicine clinic. Patients completed a survey that assessed beliefs about hypercholesterolaemia and medication-taking behaviour. Cholesterol levels were obtained from patients' medical charts.

Results. Low-density lipoprotein (LDL) cholesterol control was related to believing that hypercholesterolaemia is a stable, asymptomatic disease with severe coronary consequences, and self-report of medication adherence was related to believing that the disease has severe coronary consequences $(p s<.05)$. LDL cholesterol differences between groups low and high in various illness beliefs ranged between 0.04 and $0.24 \mathrm{mmol} / \mathrm{l}(2$ and $9 \mathrm{mg} / \mathrm{dl}$ ) which translated to between $1 \%$ and $18 \%$ lower LDL cholesterol levels.

Conclusion. The present study shows several relations that have not been previously demonstrated between better LDL cholesterol control and illness cognition, cognitions that were similar to an expert or physician's mental model of hypercholesterolaemia. The magnitude of differences in patient cholesterol levels was small but may be clinically important.

Coronary heart disease is caused by a number of factors, including elevated cholesterol levels (Knopp, 1999). Patients diagnosed with chronically elevated blood cholesterol

\footnotetext{
* Requests for reprints should be addressed to Noel Brewer, Department of Psychology, Rutgers University, I 52 Frelinghuysen Rd., Piscataway, NJ 08854, USA (e-mail: brewer@aesop.rutgers.edu).
} 
levels, a condition known as hypercholesterolaemia, are at particularly high risk for coronary heart disease and coronary-related disability and death. The most potent intervention is a new class of cholesterollowering medication that can reduce by up to half the most important component of blood cholesterol levels, low-density lipoprote in (LDL; Knopp, 1999). Lower cholesterol levels are extremely beneficial, as evidenced by the $20-50 \%$ reduction in coronary heart disease among hypercholesterolaemic patients who maintain a $10 \%$ reduction in their cholesterol (Law, Wald, \& Thompson, 1994). The present paper examines the relation of hypercholesterolaemic patients' illness beliefs to LDL cholesterol control and medication adherence.

\section{Predictors of medication adherence}

Past research on medication adherence suggests that patients will be least adherent when treatment is preventive rather than curative, when the illness is asymptomatic, and when treatment is over a long period of time (Rand, 1993). All three of these conditions exist in the case of hypercholesterolaemia. Thus, it is unsurprising that, despite the availability of effective cholesterollowering drugs, many patients do not take their medication as prescribed. Studies have reported that between 25 and $70 \%$ of patients take fewer doses of their cholesterollowering medication than prescribed (Bruckert, Simonetta, \& Giral, 1999; Furmaga, 1993; McCrindle, O’Neill, Cullen-Dean, \& Helden, 1997; Maenpaa, Manninen, \& Heinonen, 1992; Piñiero et al., 1998).

Studies that have examined the reasons for non-adherence with cholesterollowering drug regimens have focused on medication or patient characteristics. Drug characteristics related to poor adherence have typically been poor drug efficacy, side-effects such as nausea and cramping, and inconvenience caused by taking the medication in a nonpill form (Bruckert et al., 1999; Furmaga, 1993; Simons, Levis, \& Simons, 1996). Patient characteristics related to poor adherence have principally been demographic (e.g. African American ethnicity, and high socio-economic status; Avorn et al., 1998; Schrott, Bittner, Vittinghoff, Herrington, \& Hulley, 1997), lifestyle (e.g. lack of exercise, and higher body mass index; Schrott et al., 1997), or medically related (e.g. diagnosis of coronary heart disease, and being prescribed a single cholesterollowering medication; Avorn et al., 1998; Piñiero et al., 1998; Schectman \& Hiatt, 1996; Schrott et al., 1997).

We are aware of no studies that have used a psychological model such as the health belief model (Rosenstock, 1974) or the self-regulation model (Leventhal, Diefenbach, \& Leventhal, 1992) to predict medication adherence in this population. Only a handful of studies have assessed the relation of psychological factors, such as knowledge, attitudes and beliefs, to adherence with cholesterollowering medications (McGrindle et al., 1997; Piñiero, Gil, Orozco, Torres, \& Merino, 1997; Piñiero et al., 1998; Simons et al., 1996), and only one study that we are aware of has reported a significant relation between patients' adherence and their beliefs.

Bruckert et al. (1999) found that adherent patients were more likely than nonadherent patients to report that their cholesterollowering medication improved the symptoms of hypercholesterolaemia $(20 \% \mathrm{vs} .17 \%)$. In the study, patients were asked to make two summary judgments about the symptoms of their hypercholesterolaemia. They reported whe ther or not their disease caused them to experience symptoms and, if so, whe ther their medication helped to alleviate those symptoms. Bruckert et al. did not report whether patients were asked about the particular symptoms that they experienced. There was no difference between adherent (those taking more than $90 \%$ of pills) and non-adherent patients in their total number of symptoms, their knowledge about 
the impact of diet on cholesterol, knowledge about the risk factors for coronary heart disease, or the source of their health information. Patient reports of symptoms are surprising, because hypercholesterolaemia, like hypertension, is a symptomless disease.

In summary, a substantial literature on cholesterollowering medication adherence exists, but few of the studies have measured psychological variables. Only one study among patients with hypercholesterolaemia has established a link between medication adherence and a psychological variable (Bruckert et al., 1999).

Of greater medical significance is whether patients are successfully controlling their LDL cholesterol by achieving their target cholesterol level. The goal of treatment is LDL cholesterol control; this outcome is used to assess the effectiveness of cholesterollowering medication regimens. No studies that we are aware of show any significant link between LDL cholesterol control and psychological variables.

Research in this area would benefit from three additions. First, the link between psychological constructs and LDL cholesterol control should be examined. Second, the link between psychological constructs and cholesterollowering medication adherence requires further study. Third, a theoretical orientation would offer structured predictions about potential correlates of cholesterol control and pill-taking, as well as provide a context for existing findings.

\section{Self-regulation model}

The dearth of psychological research on cholesterol control and medication adherence stands in contrast to the substantial literature on other chronic diseases such as hypertension and diabetes. Psychological models that posit a relation between psychological factors and managing a chronic illness can be broadly categorized (for a review, see Horne \& Weinman, 1998) as social cognitive models such as the health belief model (Rosenstock, 1974), stage models such as the precaution adoption process model (Weinstein, 1988), and the hybrid self-regulation model (Leventhal et al., 1992). The selfregulation model is particularly appealing because of the success that several researchers have had in using the model to predict adherence in other patient populations (e.g. Heijmans, 1999; Meyer, Leventhal, \& Gutman, 1985; Weinman, Petrie, Moss-Morris, \& Horne, 1996).

According to the self-regulation model, the way that people think about their illness, that is, their illness cognitions, is organized into five discrete attributes (Leventhal et al., 1992). The first attribute, identity or symptoms, includes both the person's label for the disease and their somatic experience of the disease. The second attribute, consequences, addresses the potential and expected repercussions of the illness. The third attribute, timeline, addresses the temporal status of the disease, whether it is acute or chronic, stable or cyclical. The fourth attribute, cause, addresses the perceived covariation of the illness with other events. The fifth attribute, controllability or cure, addresses the severity of the illness and the extent to which it can be remedied.

The attributes of patients' illness cognitions have been found to be organized further into an integrated representation, called a mental model, that predicts health behaviours such as medication adherence (Lambert et al., 1998; Leventhal et al., 1992; Weinman et al., 1996). In the case of hypercholesterolaemia, a patient could have an expert-like mental model positing that hypercholesterolaemia is a symptomless disease with enduring signs and severe sequelae such as heart attacks and stroke. In one example of mental models research with hypertensive patients, a stress-based, lay mental model of hypertension depicted the disease as an acute condition with identifiable symptoms caused by stress and relieved by behaviours such as prayer or meditation (Meyer et al., 
1985). This lay model was contrasted with an expert-like (i.e. physician-like) model of hypertension as an asymptomatic chronic condition that required long-term treatment with medication, diet, and exercise. Those possessing the stress-based model had poorer blood pressure control and were more likely to miss medication.

The self-regulation model, and the above study in particular, are highly relevant to research on non-adherence with cholesterol-lowering medications. Hypercholesterolaemia and hypertension are both symptomless diseases with severe coronary sequelae. Both illnesses are chronic conditions requiring regular health behaviours by the patient to control the disease. Both are responsive to drug therapy, making medication adherence extremely important. The similarity between the diseases suggests that expert or practitioner mental models may also be related to adherence among people with hypercholesterolaemia. For the purposes of this paper, we will use the term 'expert mental model' to refer to mental models held by hypercholesterolaemic patients with reference to their illness that may be expert-like in nature but not truly expert.

The purpose of the present study was to examine the role of psychological variables suggested by the self-regulation model in predicting LDL cholesterol control and cholesterollowering medication compliance. Our primary prediction was that hypercholesterolaemic patients with expert (i.e. practitioner-like) mental models would be more successful at meeting target levels for LDL cholesterol and have a better selfreported adherence. It is logical that expert mental models should encourage medication adherence, which should, in turn, lead to lower levels of cholesterol. For this reason, we predicted that self-reported pill-taking should at least partially mediate the relation between LDL cholesterol control and mental models.

\section{Method}

\section{Participants}

In the spring of 1999 , we contacted all patients seen at a university-based general medicine clinic who had a diagnosis of hypercholesterolaemia (including familial hyperlipidaemia) and were prescribed cholesterollowering medication. The clinic, located in the northeastern USA, was part of an academic practice open to the general public. Three patients could not be contacted, because they had moved without leaving a current phone number or address. Of 275 patients contacted, 169 patients returned completed surveys (response rate $=61 \%$ ).

The sample was older adults (mean age $=67, \mathrm{SD}=10)$ and primarily male $(61 \%)$. Otherwise, the demographic characteristics of the sample were typical of the clinic where patients were recruited. Participants were predominantly white $(85 \%)$ and well educated $(M=15$ years, $\mathrm{SD}=2.6)$, and had a median annual income of US\$40,000.

\section{Procedure}

Patients were mailed a survey and a letter from their physician asking them to complete a survey and to permit access to their medical charts. Persons returning completed surveys and signed consent forms received a movie ticket worth approximately US\$5 as a compensation for being in the study. Patients' medical charts were reviewed within 4 weeks of receipt of their survey and again 3 months later to verify that the information was correct and that no new records had been added. 


\section{Chart review}

The two internal review boards that approved the study authorized a blinded review of non-responders' charts and an open review of responders' charts. The primary purpose of the review was to record patients' current cholesterol levels, including LDL cholesterol. At the same time, we also recorded their medical diagnoses and number of prescriptions to assess disease burden, their risk factors for coronary heart disease $(\mathrm{CHD})$ as explained below, and the presence or absence of $\mathrm{CHD}$.

\section{Responders}

Participants had an average of six medical diagnoses with $49 \%$ having $\mathrm{CHD}, 49 \%$ hypertension, and $21 \%$ diabetes. The cholesterollowering medications prescribed were almost exclusively statin drugs $(95 \%)$ and were tablets prescribed to be taken once a day $(99 \%)$. The most common were simvastatin $(N=56)$, atorvastatin $(N=49)$ and lovastatin $(N=29)$. The remainder of patients were prescribed pravastatin or fluvastatin or a non-statin drug (i.e. questran or gemfibrozil). Statin drugs are generally well tolerated by patients, with side-effects being mild and transient (Knopp, 1999). In the present study, only $6 \%$ of participants reported experiencing frequent side-effects from their medication.

Although four components of cholesterol were recorded from patient charts, the primary cholesterol measure of interest is LDL cholesterol, as it is the target of cholesterollowering drug therapy. The average $\mathrm{LDL}$ cholesterol reading for responders was $3.07 \mathrm{mmol} / \mathrm{l}(\mathrm{SD}=0.91)(117.9 \mathrm{mg} / \mathrm{dl}, \mathrm{SD}=35.1)$. Just over half $(54 \%)$ of participants had LDL cholesterol levels in excess of the United States National Cholesterol Education Project (1993) guidelines for persons with risk factors for and history of coronary heart disease. Nine, whose medical charts did not have a blood test with an LDL level recorded, were dropped from later analyses.

\section{Non-responders}

The medical charts of non-responders showed them to be identical to study participants for all practical purposes (see Table 1). Comparisons using $t$ tests and $\chi^{2}$ showed that those completing the survey did not differ from non-responders with respect to gender, age, weight, smoking, family history of myocardial infarction or sudden death, risk for $\mathrm{CHD}$, having $\mathrm{CHD}$, having hypertension, having diabetes, total number of diagnoses, and all measures of cholesterol with the exception of triglyceride levels. Triglyceride levels for non-responders were significantly higher than for those who completed the survey. A difference in triglyceride levels is not important, as they are unrelated to LDL cholesterol, the primary outcome variable in this study.

\section{Mental models}

Ten survey questions designed to measure the five attributes of illness cognitions (Leventhal et al., 1992) assessed participants' beliefs about hypercholesterolaemia (see Table 2). Participants answered all questions using a 5 -point Likert-like scale (labelled 'not at all' to 'very much') except for question 9, where they used a yes/no scale. For question 1 (about symptoms), participants' responses were dichotomously coded for whether or not they could tell when their cholesterol level was high. A second, openended question assessed the particular symptoms that patients used as cues to assess higher cholesterol levels. Too few responded to the latter question to analyse differences 
Table I. Mean (SD) characteristics of responders and non-responders

\begin{tabular}{|c|c|c|}
\hline & $\begin{array}{c}\text { Responders } \\
N=169\end{array}$ & $\begin{array}{c}\text { Non-responders } \\
N=106\end{array}$ \\
\hline Male gender & $61 \%$ & $52 \%$ \\
\hline Age & $67.4(10.3)$ & $67.6(11.7)$ \\
\hline Actual $\mathrm{CHD}^{a}$ & $49 \%$ & $52 \%$ \\
\hline Risk factors for CHD & $\mathrm{I} .8(\mathrm{I} .0)$ & $2.0(1.0)$ \\
\hline Number of diagnoses & $6.5(3.0)$ & $6.3(3.3)$ \\
\hline LDL cholesterol, mmol// & $3.07(.91)$ & $3.06(.99)$ \\
\hline HDL cholesterol, mmol/l & $\mathrm{I} .32(.34)$ & $1.29(.37)$ \\
\hline Total cholesterol, mmol/l & $5.25(1.10)$ & $5.34(1.07)$ \\
\hline Triglycerides, mmol/l & $4.26(2.16)$ & $5.01(2.54)^{*}$ \\
\hline
\end{tabular}

$* p<0.05$.

Note. To convert blood cholesterol levels to $\mathrm{mg} / \mathrm{dl}$, multiply by .026 .

${ }^{a}$ Percentage having one or more coronary diagnoses requiring lipid medication.

in symptoms reported. Among the six that did respond, they believed their cholesterol levels to be higher when they felt bloated, tired, fatigued, stressed, or anxious. They also mentioned chest pain and thinking less clearly.

Several of the attributes created by averaging responses to survey items were moderately correlated ( $r$ s .22 and .31), a problem for regression analysis common in studies that use the self-regulation model (e.g. Heijmans, 1999). To eliminate the problem of collinearity, we conducted an exploratory factor analysis of the 10 illness cognition items used in the present study using principal components analysis with a varimax roation. One benefit of this datareduction technique is that it produces uncorrelated factors, although we acknowledge that the particular approach that we chose is one of several that could be chosen. After examining the factor loadings and the eigenvalues, we chose a 5 factor solution for theoretical reasons based on the selfregulation model. The 5 factor solution had factors that were thematically distinct as well as having the fewest items with large loadings on multiple factors. The eigenvalues for the first five factors were $2.45,1.55,1.19,1.04$, and 0.91 . The variables' largest squared correlation with their primary factor was at least twice that with any other factor (see Table 2). Together, the factors accounted for $72 \%$ of the variability in responses. The five factors created by the factor analysis are the predictor variables used in later analyses.

The 5 factor solution for the factor analysis mapped well onto the attributes of illness cognitions in the self-regulation model, namely symptoms, consequences, cause, timeline, and cure (Leventhal et al., 1992). Two items loaded on different factors than we had expected, and we maintained the new assignments. Item number 8 loaded on the cure factor rather than the cause factor: it asked about participants' cholesterol levels being hereditary. Item number 9 loaded on the cure factor instead of the timeline factor: it asked whether participants expected to have to take their medication forever.

Designing questions assessing participants' illness cognitions was complicated by the unusual status of these patients, all of whom were taking medication to control the signs of their disease (i.e. the objective measure of elevated cholesterol) but not subjectively experienced symptoms that are presumed by physicians not to occur. 
Table 2. Rotated factor loadings of survey items on to the five attributes of hypercholesterolaemia illness cognitions

Illness cognition attribute

Survey item

Symptoms Consequences Timeline Cause Cure

I. Can you tell when your cholesterol levels are high?

2. Do you think that high cholesterol can increase your risk of having a stroke?

3. Do you think that high cholesterol can increase your risk of having a heart attack?

4. Do you think that your cholesterol levels fluctuate a lot, even when the amount of medication you are taking remains constant?

5. Do you think stress influences your cholesterol level?

6. Do you think your level of physical activity influences your cholesterol level?

7. Do you think your choice of foods influences your cholesterol level?

8. Do you think your cholesterol level is hereditary?

9. Do you think that you will have to take cholesterol-lowering medication for the rest of your life?

10. Do you think that you can be cured of high cholesterol?
.99

$-$

$-$

$-$

.93

.91

89

$\begin{array}{ccccc}- & - & - & .80 & - \\ - & - & - & .77 & - \\ - & .40 & - & .65 & - \\ - & - & - & - & .64 \\ - & - & - & - & .62 \\ - & - & & & \\ - & - & - & - & -.73\end{array}$

Note. The questions shown are the original 10 items used in the survey. Numbers represent the correlations of each survey question with each of the five factors. Correlations less than $.32\left(R^{2} \leq .10\right)$ are not shown. Participants answered all questions using a 5-point Likert-like scale except for No. 9 where they used a yes/no scale.

The question assessing changes over time (i.e. Timeline) had to consider that some patients would have a diagnosis of hypercholesterolaemia but normal cholesterol levels, because their medication was effective. Asked if they would have elevated cholesterol levels for the rest of their life (a common way to assess Timeline), they might sensibly answer 'No', even though they believed that they would have hypercholesterolaemia forever. For this reason, instead of asking about a chronic/acute distinction, we opted to examine participants' belief in stable/cyclic changes in their cholesterol levels (assuming a stable level of medication taking). A limitation of this strategy is that the item possibly could have been interpreted by participants as asking about how effective their medication was rather than how variable their illness was over time.

The items assessing Cure shared the common theme that hypercholesterolaemia is an incurable disease. Thus, item 8 about heredity loaded on the Cure factor, suggesting 
that hypercholesterolaemia is genetically caused and thus not curable (although possibly controllable).

\section{Measures of adherence}

Patient adherence was measured by asking patients whe ther they were adhering to their cholesterollowering medication regimen, and by examining their blood tests to see whether they were adhering to their LDL cholesterol treatment goal.

\section{Self-reported pill-taking}

Three survey items assessed participants' adherence with their cholesterollowering drug regimen. One asked how often, over the last 2 weeks, they took fewer pills than prescribed. Two other questions asked whether, over the past week and over the past 6 months, they took their medication exactly as prescribed. (A fourth item asking about the number of increased doses in the past 2 weeks was dropped from the analyses, because participant responses had almost no variance, with $98 \%$ of participants answering 'never'.)

The three items were collapsed to create a single medication adherence score (Cronbach's $\alpha=.71$ ) in order to streamline the main analyses and because they were intercorrelated $(r s=.35-.57)$. The medication adherence score was formed by categorizing participants into one of two types. Participants were categorized as adherent if they reported no decreased medication doses in the past 2 weeks and responded that they always took their medication exactly as prescribed over the past week and over the past 6 months. We categorized as non-adherent all participants who reported less-thanperfect adherence on any one of the three measures. By this method, $31 \%$ of the patients were categorized as non-adherent. Four participants were dropped from later analyses, because they did not answer these adherence questions.

\section{LDL cholesterol control}

We assessed patients' CHD risk to identify their LDL cholesterol treatment goal from which we subtracted their actual LDL cholesterol level in order to create an LDL cholesterol control score. Positive LDL cholesterol control scores indicated acceptable cholesterol control, and higher scores indicated better control.

First, each patient's CHD risk was assessed using the National Cholesterol Education Program (National Cholesterol Education Program, 1993) guidelines. The National Cholesterol Education Program states that independent risk factors for $\mathrm{CHD}$ are diabetes, hypertension, current smoker, family history of myocardial infarction, or sudden death before age 55 in male first-degree relative or before age 65 in female first-degree relative, and male older than 45 or female older than 55. Patients with highdensity lipid (HDL) cholesterol levels below $0.91 \mathrm{mmol} / \mathrm{dl}(35 \mathrm{mg} / \mathrm{dl})$ have an additional $\mathrm{CHD}$ risk factor, and those with $\mathrm{HDL}$ greater than $1.56 \mathrm{mmol} / \mathrm{dl}(60 \mathrm{mg} / \mathrm{dl})$ have one fewer $\mathrm{CHD}$ risk factor.

Second, the National Cholesterol Education Program (1993) guidelines for treatment of hypercholesterolaemia were used to establish LDL cholesterol treatment goals. The LDL cholesterol treatment goal for patients with fewer than two risk factors for CHD is $4.16 \mathrm{mmol} / \mathrm{l}(160 \mathrm{mg} / \mathrm{dl})$. The goal for patients with two or more risk factors is $3.38 \mathrm{mmol} / \mathrm{l}(130 \mathrm{mg} / \mathrm{dl})$. The goal for people with a diagnosis of $\mathrm{CHD}$ is $2.60 \mathrm{mmol} / \mathrm{l}$ $(100 \mathrm{mg} / \mathrm{dl})$. Recent research has suggested that diabetics receive target levels as stringent as patients with CHD (Ansell, Watson, \& Fogelman, 1999; Knopp, 1999; 
National Cholesterol Education Program, 2001). As the research recommending this change became available after patient LDLlevels were measured, the new guideline was unlikely to have been used by doctors in treatment decisions, and thus we did not consider it when making target calculations.

\section{Results}

To examine the psychological correlates of patients' disease management, we first tested whether illness cognitions predicted LDL cholesterol control, the outcome measure of primary interest. Next, we tested whether illness cognitions predicted medication adherence. Finally, we tested whether medication adherence would mediate the relation between illness cognitions and $\mathrm{LDL}$ cholesterol control.

\section{LDL cholesterol control}

As noted earlier, an LDL cholesterol control score was calculated to take into account patients' differing treatment goals. Positive values for LDL cholesterol control indicate having met the $\mathrm{LDL}$ treatment goal, and higher scores indicate better control.

LDL cholesterol control was related to patients' illness cognitions about the symptoms, consequences, and timeline of hypercholesterolaemia (see Table 3 ). The other two attributes of illness cognitions, cause and cure, were not signific antly related to LDL cholesterol control. A multiple linear regression used illness cognitions (i.e. symptoms, consequences, timeline, cause, and cure) to predict patients' continuous LDL cholesterol control scores. The regression, and all other analyses reported here, covaried out the effects of medical (having CHD, hypertension or diabetes diagnosis, smoker, number of medications, and medication side-effects) and demographic (age, gender, white ethnicity, education) variables. Although we asked participants what they believed to be a healthy level of LDLcholesterol, fewer than half answered the question, thus making it unsuitable to use as a covariate. When the analyses were performed without the covariates, the results did not differ substantially from those presented except as noted. The adjusted $R^{2}$ for the model was .15 .

\section{Symptoms}

Participants had worse LDLcholesterol control when they believed that high cholesterol caused symptoms such as fatigue and tiredness $(\beta(140)=-.16, p<.05)$. To translate this effect into meaningful units, we dichotomized the symptoms variable at the median and looked at LDL cholesterol control for each group. Participants low in symptoms beliefs were $.04 \mathrm{mmol} / \mathrm{l}(1.5 \mathrm{mg} / \mathrm{dl})$ closer to their LDL cholesterol tre atment goal than participants high in such beliefs. When compared with our sample's mean LDL level ( $=3.07 \mathrm{mmol} / \mathrm{l}, 117.9 \mathrm{mg} / \mathrm{dl})$, the difference between the two groups in LDLcholesterol control was $1 \%$

\section{Consequences}

Participants had better LDLcholesterol control when they believed that high cholesterol increased their risk for heart attack and stroke $(\beta(140)=.23, p<.005)$. Participants low in consequence beliefs had LDL cholesterol control scores that were $0.24 \mathrm{mmol} / 1$ $(9.1 \mathrm{mg} / \mathrm{dl})$ higher than those high in such beliefs. The difference between the two groups in LL cholesterol control was $8 \%$ 


\section{Timeline}

Patients had better LDL cholesterol control when they believed that their cholesterol levels were stable over time $(\beta(140)=-.17, p<.05)$. Participants low in timeline beliefs had LDLcholesterol control scores that were $0.21 \mathrm{mmol} / \mathrm{l}(8.0 \mathrm{mg} / \mathrm{dl})$ higher than those high in such beliefs. The difference between the two groups in LDL cholesterol control was $7 \%$ When covariates were not used in the regression, the direction of the relation remained negative, but timeline beliefs were no longer a significant predictor of LDL cholesterol control $(\beta(140)=-.11$, n.s. $)$.

\section{Self-reported pill-taking}

Participants' beliefs about the consequences of hypercholesterolaemia predicted their self-reported adherence with their medication regimens. The other four attributes of illness cognitions - symptoms, timeline, cause, and cure - showed no relation to selfreported adherence (see Table 3 ). A multiple logistic regression used illness cognition attributes to predict patients' dichotomous medication compliance. The $R^{2}$ for the model was .17.

Table 3. Relation between illness cognitions and LDL cholesterol control and medication adherence

$\begin{array}{cc}\mathrm{LDL}^{-} \text {cholesterol control } \\ \beta & \text { Self-reported adherence } \\ \beta & \end{array}$

$\begin{array}{lcc}\text { Illness cognition attributes } & & \\ \text { Symptoms } & -.16^{*} & .15 \\ \text { Consequences } & .23^{* *} & -.11 \\ \text { Timeline } & -.17^{*} & .13 \\ \text { Cause } & .10 & .09 \\ \text { Cure } & -.04 & \\ \text { Covariates } & & -.04 \\ \text { CHD } & -.33^{*} & -.12 \\ \text { Hypertension } & -.05 & -.22 \\ \text { Diabetes } & .12 & -.09 \\ \text { Smoker } & .11 & .08 \\ \text { Number of medications } & -.03 & -.37^{* *} \\ \text { Medication side-effects } & -.06 & .14 \\ \text { Age } & .16 & .07 \\ \text { Male gender } & -.13 & -.06 \\ \text { White ethnicity } & -.01 & -.04 \\ \text { Education } & .06 & \end{array}$

$* p<.05 ; * * p<.005$.

${ }^{a}$ LDL cholesterol control calculated as the LDL cholesterol treatment goal (based on National Cholesterol Education Project guidelines) minus the LDL cholesterol level.

\section{Consequences}

Participants reported a better adherence when they believed that high cholesterol increases heart attack and stroke risk $(\beta(140)=.28, p<.05)$. To translate this effect into meaningful units, we dichotomized the consequences variable at the median and looked at the rate of medication adherence for each group. Of patients high in consequence 
beliefs, $76 \%$ were adherent, whereas $62 \%$ of the group low in consequence beliefs were adherent.

\section{Self-reported pill-taking predicting LDL cholesterol control}

Self-reported pill-taking predicted LDL cholesterol control. A multiple linear regression used self-reported pill-taking to predict patients' continuous LDL control scores. The adjusted $R^{2}$ for the model was .12. A higher self-reported adherence was significantly related to higher levels of $\mathrm{LDL}$ cholesterol control $(\beta(140)=.25, p<.005)$. Adherent patients had LDL cholesterol control scores that were $0.40 \mathrm{mmol} / \mathrm{l}(15.5 \mathrm{mg} / \mathrm{dl})$ lower than non-adherent patients. The difference between the two groups in LDL cholesterol control is $13 \%$ Covarying out the effects of illness cognitions did not affect the relation between self-reported pill-taking and LDL cholesterol control.

\section{Mediational analysis}

A mediational analysis tested whether the relation between illness cognitions and LDL cholesterol control is mediated by self-reported pill-taking. Three of the four steps required for mediation have been reported in the previous three sections (i.e. examining the relation of illness cognitions to LDL cholesterol control and self-reported pill-taking, and the relation of the latter two to each other). To conduct the final step required for mediational analysis, all five attributes of illness cognitions, as well as self-reported pilltaking, were entered into a multiple linear regression predicting LDLcholesterol control (Baron \& Kenny, 1986).

It is appropriate to report the mediational effect only for consequences. A mediational analysis is appropriate when there is a relation between illness cognitions and LDL cholesterol control, a relation between illness cognitions and self-reported medication taking, and a relation between the self-report and LDL cholesterol control (after controlling for illness cognitions). The symptoms and timeline attributes cannot be part of a mediational relation, because neither is signific antly related to self-reported adherence.

Self-reported pill-taking negligibly affected the relation between consequence illness cognitions and LDL cholesterol control. The $\beta$ weight dropped from its previous level of .23 to .18 but remained significant after partialling out the effects of self-reported adherence $(\beta(140)=.18, p<.03)$. The small size of the change and the inability of selfreported adherence to mediate other illness cognition attributes' effect suggests that the link between illness cognitions and LDL cholesterol control is influenced only slightly by medication adherence for this patient population.

\section{Discussion}

The present study explored the relationships between illness cognitions and two measures: achievement of LDL treatment goals and self-reported cholesterollowering medication taking. Our findings and their implications can be summarized in two points. First, several previously unknown relations between patients' illness cognitions and their cholesterol levels as well as their medication adherence were found. Improved control and adherence were found among patients whose illness cognitions matched that of an expert model of hypercholesterolaemia. Second, these relations, although small, could have important implications for hypercholesterolaemic patients' long-term coronary health. 


\section{Limitations}

Before discussing our findings in detail, it is important to consider several limitations. It is not possible to know whether changes in patient beliefs would lead to changes in adherence or control, as the study's cross-sectional design does not permit drawing causal inferences. Although the correlations we have noted have the potential for being clinically significant, the effect sizes reported here are very small. The size of the relations may be due in part to restriction in range caused by using a patient population whose cholesterol levels are strongly affected by a medication that most were very compliant in taking. Our sample may not be completely representative of other hypercholesterolaemic patients, as our sample was predominantly white and well educated. The lack of a relation between self-reported pill-taking and two illness cognition attributes, symptoms and timeline, may be caused by patients over-reporting compliance or not accurately recalling past behaviour.

Finally, several limitations relate to the measurement of illness cognitions, limitations that could have been addressed by using a previously normed illness cognition scale, such as the Illness Perception Questionnaire (Weinmann et al., 1996). The single item measures used for Symptoms and Timeline may have limited the power to detect a relationship to pill-taking. The items that measure Timeline and Cure differ from those used in previous research. Past research (e.g. Meyer et al., 1985) examined Timeline as an acute/chronic construct, whereas we examined it as a stable/cyclic construct. The items in the Cure factor share the sense of whether or not hypercholesterolaemia is incurable but include an item that is often used to measure Cause (i.e. cholesterol levels are hereditary). Despite the limitations just discussed, the present study expands our understanding of psychosocial influences on how patients manage chronically elevated cholesterol.

\section{Expert models of hypercholesterolaemia}

The present study used H Leventhal's self-regulation model (Leventhal et al., 1992) as an explanatory and predictive tool. The model's attributes of illness cognition proved to be a useful tool for generating new hypotheses about psychological predictors of adherence and blood cholesterol levels. Of the five attributes of patients' illness cognitions, three proved to be important in predicting medication adherence and cholesterol levels: consequences, symptoms, and timeline. The predictions about consequences could be made equally well by other health models such as the healthbelief model (Rosenstock, 1974). The predictions about symptoms and timeline are unique to the self-regulation model.

The first finding was that patients who strongly believed that the consequences of high cholesterol levels were heart attack and stroke had better medication adherence and better LDL cholesterol control. Believing that high cholesterol has multiple, severe consequences is highly rational and consonant with an expert medical model of the illness. Our medication adherence finding is counter to the findings of Piñiero et al. (1997), who failed to find any relation to consequence beliefs. One explanation is that Piñero et al. used a different measure of beliefs about the consequences of hypercholesterolaemia. The authors asked participants to name one organ affected by their high cholesterol, perhaps causing people who had no opinion to guess, thus increasing the measure's noise and damaging its predictive ability.

Our second finding was that patients who believed that high cholesterol produces physical symptoms showed poorer LDL cholesterol control. This provides additional 
support for our hypothesis of an expert model of the disease: better cholesterol control was found among those believing, as doctors do, that high cholesterol does not cause symptoms. The absence of a relation between symptom beliefs and self-reported adherence parallels the findings of Bruckert et al. (1999), who also found that adherent patients reported similar levels of symptoms to those who were non-adherent.

Our third finding was that patients were more likely to meet their LDL targets when they believed the timeline of their disease to be stable, that is, not characterized by cyclic changes in cholesterol levels. Timeline did not show a relation to self-reported adherence. These results again show that people with an expert model of high cholesterol, believing that people taking cholesterollowering medication have stable cholesterol levels, demonstrate better LDL cholesterol control.

Overall, our prediction that participants with an expert model of hypercholesterolaemia would be more adherent was partially confirmed. The exceptions were the two attributes, cause and cure, that did not show any relation to either measure of adherence. Our findings for cause and cure are consonant with past hypercholesterolaemia research. Piñiero et al. (1997) also did not find a relation between adherence (measured by self-report, LDL cholesterol control, and surprise pill count) and beliefs about the cause and cure of hypercholesterolaemia.

We have taken the perspective that expert-like illness cognitions encourage improved medication adherence and LDL cholesterol control. As the present study was cross-sectional in design, it is possible that the opposite relation holds such that patients' adherence and LDL cholesterol control are indirectly influencing their illness cognitions. Patients with the most severe cases of hypercholesterolaemia may be treated the most aggressively, thus lowering their cholesterol levels. At the same time, these patients' physicians may be more proactive in educating them about the symptoms, consequences, and timeline of their disease. This account requires that those with the highest cholesterol would end with the lowest levels after treatment, a scenario that seems unlikely.

Our finding of improved adherence among patients with expert mental models mirrors previous research on mental models of other chronic diseases such as hypertension. Meyer et al. (1985) found that hypertensive patients who had an expert model of their disease showed higher levels of medication adherence and better blood pressure control. The expert model was characterized by believing hypertension to be a symptom-less chronic condition (the 'silent killer') that required long-term treatment with medication, diet, and exercise. Benefits of having an expert model of one's disease were also found in the present study.

\section{Clinical importance and conclusions}

The relation between illness cognitions and LDL cholesterol control was reliable but small. Differences between groups low and high in various illness beliefs ranged between 0.04 and $0.40 \mathrm{mmol} / \mathrm{l}(2$ and $9 \mathrm{mg} / \mathrm{dl})$, which translates to having approximately a 1-8\%lower level of LDLcholesterol. Combining all three correct beliefs would translate into a $16 \%$ drop in cholesterol. These small differences in LDL cholesterol levels may have substantial clinical implications. Patients who are able to maintain a $10 \%$ reduction in cholesterol have a $20-50 \%$ lower incidence of coronary heart disease (Law et al., 1994). As the relation between cholesterol and coronary morbidity and mortality is continuous and graded (Stamler et al., 2000), it is possible that differences in the range that we identify are clinically important. While a prospective study would be required to 
apply the findings of Law et al. to the present study, the correlations presented here are promising.

Interventions to increase cholesterollowering medication adherence have shown a very low rate of success. Only a handful of studies that used comprehensive programmes targeting patients with coronary heart disease have shown improvements in cholesterol levels (for a review, see Dusseldorp, van Elderen, Maes, Muelman, \& Kraaji, 1999). The present study suggests three beliefs that future cholesterollowering interventions could target. Educating patients that their disease can have substantial health consequences, does not have identifiable symptoms, and has a noncyclic timeline may be an effective way to promote LDL cholesterol control.

\section{Acknowledgements}

The authors wish to thank Howard Leventhal and Richard Contrada for their assistance with this study, and two anonymous reviewers for their comments on a draft of this paper. Derick Chae, Elliot Coups, Noga Delshad, Jill Fgeth, Azi Ghaffari, Jeff Gonzales, Murtaza Manaqibwala, Julie Markman, Laura Niedermayer, Matt Steiner, Beth Silver, Jeff Sorge, Alexa Tapanes, Gladys Tiu, and Anthony Yang assisted with collecting data for this study.

\section{References}

Ansell, B. J., Watson, K. E, \& Fogelman, A. M. (1999). An evidence-based assessment of the NCEP Adult Treatment Panel II guidelines. Journal of the American Medical Association, 282, 2051-2057.

Avorn, J., Monette, J., Lacour, A, Bohn, R., Monae, M., Mogun, H, \& LeLorier, J. (1998). Persistence of use of lipid lowering medications: Acrossnational study. Journal of the American Medical Association, 279, 1458-1462.

Baron, R. M. \& Kenny, D. A. (1986). The moderator-mediator variable distinction in social psychological research: Conceptual, strategic, and statistical considerations. Journal of Personality and Social Psychology, 51, 1173-1182.

Bruckert, E., Simonetta, C., \& Giral, P. (1999). Compliance with fluvastatin treatment characterization of the noncompliant population within a population of 3854 patients with hyperlipidemia: CREOLE study team. Journal of Cinical Epidemiology, 52, 589-594.

Dusseldorp, E, van Elderen, T., Maes, S., Muelman, \& Kraaj, V. (1999). A meta-analysis of psychoeducational programs for coronary heart disease patients. Health Psychology, 18, 506-519.

Furmaga, E. M. (1993). Pharmacist management of a hyperlipidemia clinic. American Journal of Hospital Pharmacy, 50, 91-95.

Heijmans, M. (1999). The role of patients' illness representations in coping and functioning with Addison's disease. British Journal of Health Psychology, 4, 137-149.

Horne, R., \& Weinman, J. (1998). Predicting treatment adherence: An overview of theoretical models. In L B. Meyers \& K. Midence (Eds.), Adherence to treatment in medical conditions. Amsterdam: Harwood Academic.

Knopp, R. H (1999). Drug treatment of lipid disorders. New England Journal of Medicine, 341, 498-511.

Lambert, J. F., Contrada, R. J., Jahn, E. G., Idler, E. L, Hudson, S. V., Leventhal, E A., \& Leventhal, H (1998). Common-sense models of hypertension in African Americans. Unpublished manuscript.

Law, M. R., Wald, N. J., \& Thompson, S. G. (1994). By how much and how quickly does reduction in serum cholesterol concentration lower risk of ischaemic heart disease? British Medical Journal, 308, 367-373. 
Leventhal, H, Diefenbach, M, \& Leventhal, E. A. (1992). Illness cognition: Using common sense to understand treatment adherence and affect cognition interactions. Cognitive Therapy and Research, 16, 143-163.

McGrindle, B. W., O'Neill, M. B., Cullen-Dean, G., \& Helden, E. (1997). Acceptability and compliance with two forms of cholesterolamine in the treatment of hypercholesterolemia in children; A randomized, crossover trial. Journal of Pediatrics, 130, 266-273.

Maenpaa, H, Manninen, V., \& Heinonen, O. P. (1992). Compliance with medication in the Helsinki heart study. European Journal of Cinical Pharmacology, 42, 15-19.

Meyer, D., Leventhal, H, \& Gutmann, M. (1985). Common-sense models of illness: The example of hypertension. Health Psychology, 4, 115-135.

National Cholesterol Education Program (1993). Summary of the second report of the NCEP expert panel on detection, evaluation, and treatment of high blood cholesterol in adults. Journal of the American Medical Association, 269, 3015-3023.

National Cholesterol Education Program (2001). Executive summary of the third report of the National Cholesterol Education Program (NCEP) Expert Panel on Detection, Evaluation, and Treatment of High Blood Cholesterol in Adults (Adult Treatment Panel III). Journal of the American Medical Association, 285, 2486-2497.

Piñiero, F, Gil, V., Orozco, D., Torres, M. T., \& Merino, J. (1997). Validez de 6 metodos indirectos para valorar el cumplimiento del tratamiento farmacologico en las dislipemias \{Validity of six indirect methods of assessing compliance with drugs treatment in cases of lipaemia\}. Atencion Primaria, 19, 465-468.

Piñiero, F., Gil, V., Pasotr, R., Donis, M., Torres, M. T., \& Merino, J. (1998). Factores implicados en el incumplimiento del tratamiento farmacologico e las dislipemias fFactors involved in non-compliance with drug treatment in cases of dislipidaemia $\}$. Atencion Primaria, 21, $425-430$.

Rand, C. S. (1993). Measuring adherence with therapy for chronic diseases: Implications for the treatment of heterozygous familial hypercholesterolemia. American Journal of Cardiology, 72, 68D-74D.

Rosenstock, I. (1974). The health belief model and preventive behavior. Health Education Monographs, 2, 354-386.

Schectman, G., \& Hiatt, J. (1996). Drug therapy for hypercholesterolemia in patients with cardiovascular disease: Factors limiting achievement of lipid goals. American Journal of Medicine, 100, 197-204.

Schrott, H. G., Bittner, V., Vittinghoff, E, Herrington, D. M. \& Hulley, S. (1997). Adherence to National Cholesterol Education Program treatment goals in postmenopausal women with heart disease. Journal of the American Medical Association, 277, 1281-1286.

Simons, L A, Levis, G., \& Simons, J. (1996). Apparent discontinuation rates in patients prescribed lipidtowering drugs. Medical Journal of Australia, 164, 208-211.

Stamler, J., Daviglus, M. L, Garside, D. B., Dyer, A. R., Greenland, P., \& Neaton, J. D. (2000). Relationship of baseline serum cholesterol levels in 3 large cohorts of younger men to longterm coronary, cardiovascular, and all-cause mortality and to longevity. Journal of the American Medical Association, 284, 311-318.

Weinman, J., Petrie, K. J., Moss-Morris, R., \& Horne, R. (1996). The illness perception questionnaire: Anew method for assessing the cognitive representation of illness. Psychology and Health, 11, 431-445.

Weinstein, N D. (1988). The precaution adoption process. Health Psychology, 7, 355-386.

Received 27 October 2000; revised version received I 2 July 200 I 